\title{
Exploring the networked image in 'post' art practices
}


- Networked artist:

- Networks as theme, form, context or site;

- Networks pre-existing or created by practice.

- Multimedia in form, transdisciplinary in method. 


\section{Works}

- Four networked works:

- Performative theme, form, context or site;

- Similar forms - weblogs, digital photography, moving image;

- Shared themes and procedures. 


\section{Works}

\section{This is Real Virtuality (2014)}

http://this-is-real-virtuality.tumblr.com/

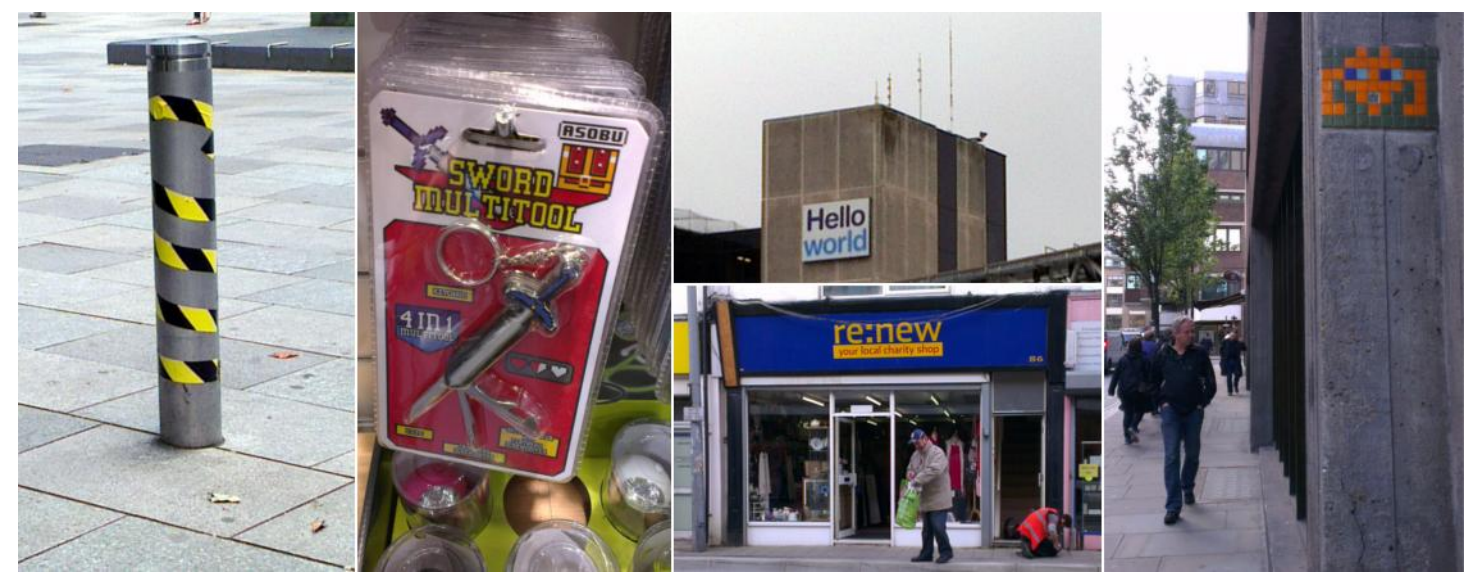

- Concept: Colliding virtu/re-alities; merging of 'virtual' and 'real' spaces.

- Process: Photographing 'real' spaces influenced by 'virtual' space. Improvised narrative.

- Form: Images and texts produced uploaded to a weblog over a year. 


\section{Works}

\section{We Entomb Memoir (2015)}

\section{http://weentombmemoir.tumblr.com/}

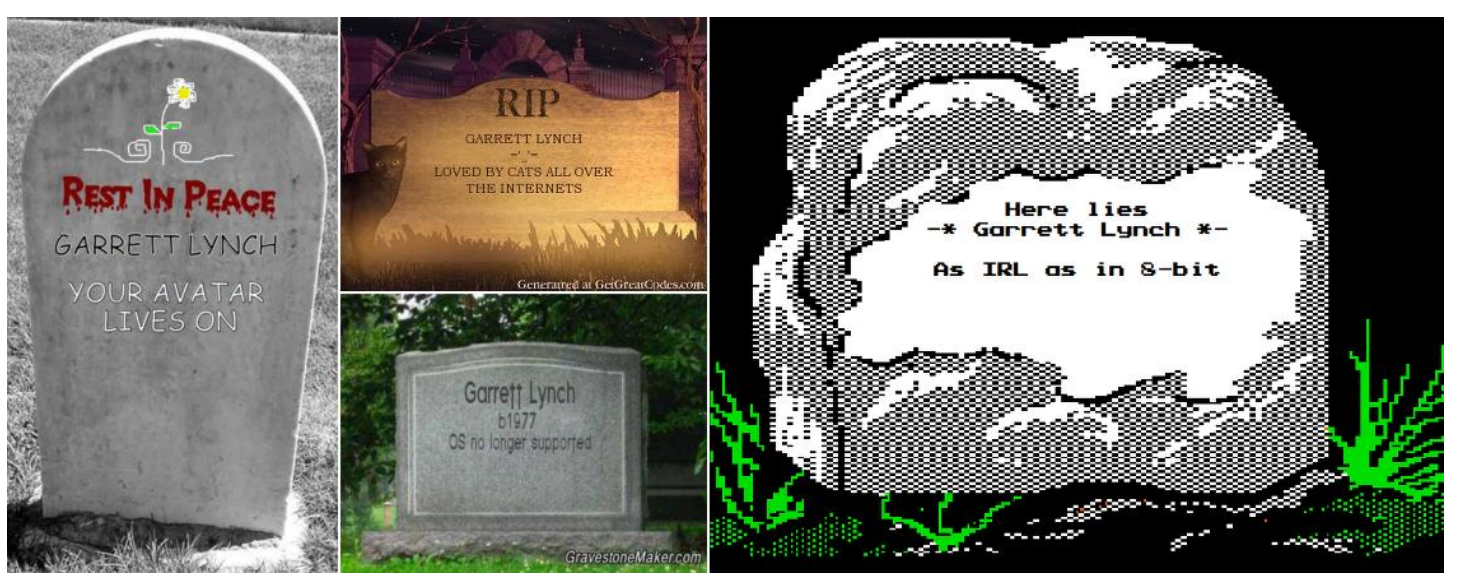

- Concept: Exploration of self-portraiture and mortality, appropriated media through media détournement (Debord, 1957) and postproduction (Bourriaud, 2005).

- Process: Process-based actions performed online with image macro generators.

- Form: Images compiled/presented as weblog. 


\section{Works}

\section{Transformations: Actions to Matter / Matter to Actions (2015 - ongoing) http://www.asquare.org/work/transformations/}

MY DETAILS

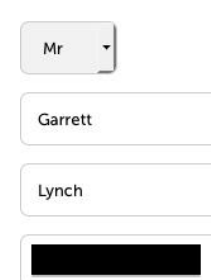

31

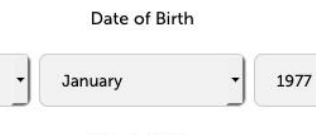

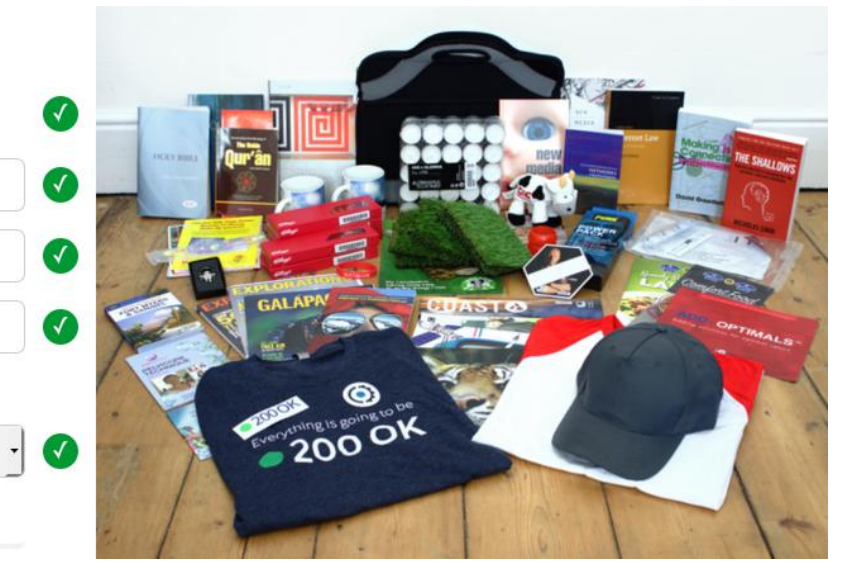

- Concept: Manifesting 'real' items (matter) from online performance (actions).

- Process: Actions to Matter - actions performed online, documented as screenshots, posted to weblog. Matter to Actions - items gathered photographed, posted to weblog and sold online.

- Form: Screenshots and photographs uploaded throughout the duration of the work. Website tracks and graphs all actions. 


\section{Works}

\section{Tran\$actions (2015 - ongoing)}

\section{http://trans-act-ions.tumblr.com/}

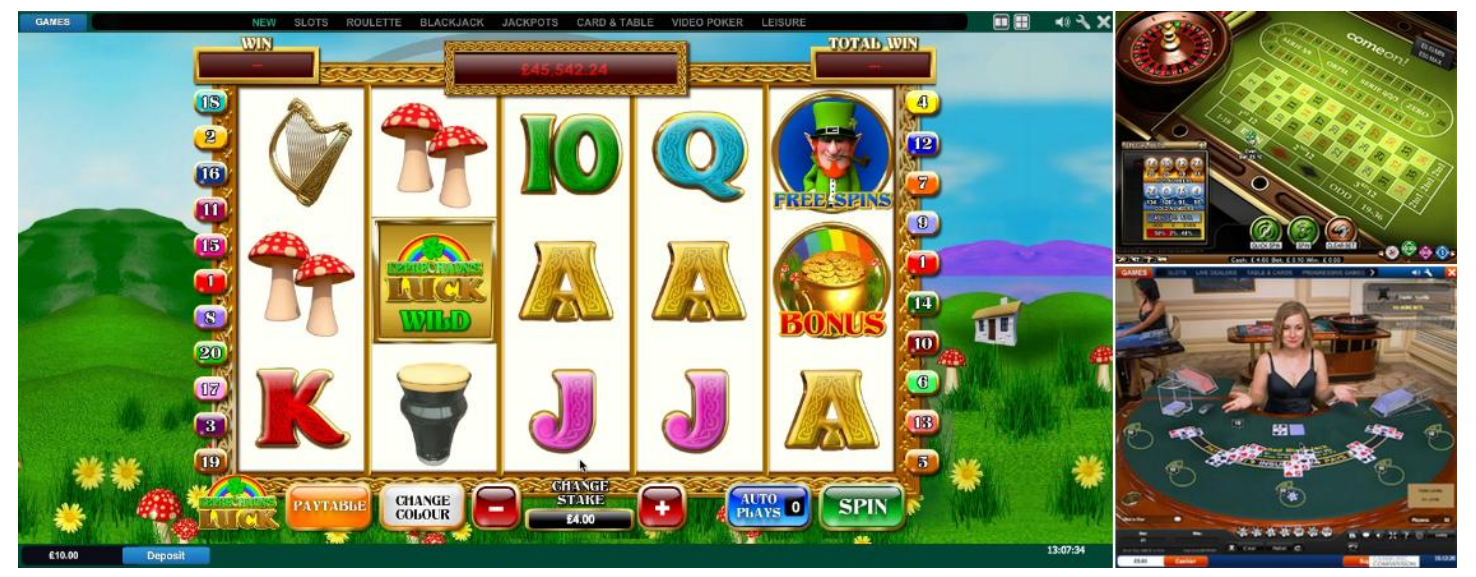

- Concept: Exploration of gambling online (play) as performative actions.

- Process: Gambling employs introductory or bonus offers. Each game considered a performative action, actions continue until the offer is exhausted.

- Form: Actions documented as screencasts, uploaded to a video sharing site and a weblog throughout the duration of the work. Weblog tracks and graphs all actions. 
- Exploit existing networks:

- Form, materials or space of those networks (We Entomb Memoir, Tran\$actions);

- Create networks:

- Between non-digital and digital or 'real' and 'virtual' (This is Real Virtuality, Transformations: Actions to Matter / Matter to Actions);

- Networks as transformative. 


\section{Themes}

- Relationship between digital and physical, 'virtual' and 'real' space:

- Problem terms - 'virtual' and 'real';

- What is performative:

- Broken down into actions;

- Occur over various times, spaces etc. 


\section{Networked Image}

- Not post-art practice but an exploration of the concept of 'post' within art practice:

○ Post-internet;

- Post-digital;

- Post-photographic;

- Post-screen;

- As well as post-disciplinary, postmedia (Guattari, 1990; Manovich, 2000) and postproduction (Bourriaud, 2005). 


\section{Networked Image}

- Photographic imagery documenting performance

- Photographic imagery is also one of the objectives of performance. 


\section{Networked Image}

- Photographic imagery documenting performance:

- Photographic imagery is also one of the objectives of performance.

- Nothing new - performance for camera long been acknowledged in performance (O'Dell, 1997).

- Photographs also positioned within networks, viewed through screens to look back into a network reminding viewer of theme/form/context/site of the work. 


\section{Thank you}

\section{Contact:}

\section{garrett@asquare.org}

Contributions welcome and appreciated for Transformations: Actions to Matter / Matter to Actions: http://www.asquare.org/work/transformations/ 


\section{References}

Bolter, J. D., (2005). Windows and Mirrors: Interaction Design, Digital Art, and the Myth of Transparency. Cambridge, Massachusetts: MIT Press.

Bourriaud, N., (2005). Postproduction: Culture as screenplay: how art reprograms the world. 2 nd ed. New York: Lukas \& Sternberg.

Debord, G., (2006). Report on the Construction of Situations. Situationist International Anthology. Translated from French by K. Knabb. Berkeley, California: Bureau of Public Secrets.

Guattari, F., (1990). Entering the Post-Media Era. In: S. Lotringer, ed. 2009. Soft Subversions: Texts and Interviews 1977-1985. Los Angeles, CA: Semiotext(e). Ch.24.

Manovich, L., (2000). Post-Media Aesthetics. [online] manovich.net. Available at: < http://manovich. net/index.php/projects/post-media-aesthetics> [Accessed 05/06/16].

O'Dell, K., (1997). Displacing the haptic: performance art, the photographic document, and the 1970s. Performance Research, 2 (1). pp.73-81.

Sloan, R., (2012). Dancing the flip-flop. [online] Robinsloan.com. Available at: <https://www. robinsloan.com/notes/flip-flop/> [Accessed 04/06/16]. 